(6)

OPEN ACCESS

\title{
Trends in the method and gestational age of abortion in high-income countries
}

\author{
Anna Popinchalk, ${ }^{1}$ Gilda Sedgh ${ }^{2}$
}

\begin{abstract}
- Additional material is published online only. To view please visit the journal online (http://dx.doi.org/10.1136/ bmjsrh-2018-200149).
\end{abstract}

${ }^{1}$ Guttmacher Institute, New York, New York, USA

${ }^{2}$ Guttmacher Institute, New York, New York, USA

\section{Correspondence to}

Anna Popinchalk, Guttmacher Institute, New York NY 10038, USA; apopinchalk@guttmacher. org

Received 6 June 2018 Revised 31 January 2019 Accepted 5 February 2019 Published Online First 8 March 2019

\section{Check for updates}

(C) Author(s) (or their employer(s)) 2019. Re-use permitted under CC BY-NC. No commercial re-use. See rights and permissions. Published by BMJ.

To cite: Popinchalk A, Sedgh G. BMJ Sex Reprod Health 2019;45:95-103.

\begin{abstract}
Background Examining the distribution of abortions by method of abortion and gestational age at time of termination provides insight about the options women may have to terminate their pregnancies. Comparing these distributions across countries and over time is an important step toward understanding the factors that can drive these distributions, including regulations and practices related to the provision of abortion services, and women's preferences and needs.

Methods We sought official statistics on gestational age and method of abortion for all high-income countries with liberal abortion laws. For the 24 high-income countries with available data, we calculated percentage distributions of abortions by gestational age of pregnancy and method of abortion for 2017 or the most recent year for which data were available, and assessed trends in the preceding 10 years whenever possible.

Results Medication (or medical) abortion accounts for at least half of all abortions in the majority of countries. In the majority of countries over $90 \%$ of all abortions were completed before 13 weeks, and more than two-thirds of abortions occurred before the first 9 weeks of gestation. Over the past 10 years there has been an increase in both the proportion of abortions that were medication abortions and the proportion that were obtained before 9 weeks gestation.

Conclusions These findings highlight changes in abortion provision in the past decade. More research is needed to understand whether the observed distributions are a function of women's preferences or of barriers to the timing and type of care they would prefer.
\end{abstract}

\section{INTRODUCTION}

Abortion is a common event in women's lives: in 2010-2014, an estimated 56 million abortions occurred, and nearly 8 million occurred in high-income countries. ${ }^{1}$ High-income countries with liberal abortion laws often have accessible and

\section{Key messages}

- In the majority of countries, medication (or medical) abortion accounts for at least half of all abortions, and this has increased over the past 10 years.

- In the majority of countries, at least $90 \%$ of abortions occur under 12 weeks, and the proportion of abortions obtained earlier than 9 weeks has increased in most countries.

- Findings suggest improvements in access to timely care and a choice of methods in some countries, although research is needed to understand if the observed distributions are a function of women's preferences or of barriers to care.

reliable abortion data, resulting in a unique opportunity to compare abortion service provision across countries. Data on the method and gestational age of abortion can provide insight on abortion provision within a country, including the options women have to terminate their pregnancies. Trend data on these characteristics can show whether abortion care within a country has changed over time.

This review provides the first cross-national comparison of the method and gestational age of abortion in high-income countries, and of trends in these characteristics over time. Comparing how and when pregnancies are terminated across countries and over time is an important first step toward understanding the factors influencing the findings. These factors might include service regulations, provider practices and preferences, and women's preferences. Such a review can also be used to identify departures from typical patterns, and explore their causes. Ultimately these data are of 
use to policymakers, programme planners and service providers to ensure women have access to safe, highquality and timely abortion care.

\section{METHODS}

Official statistics on the number of legal abortions by gestational age and method of abortion were sought for the 40 high-income countries with liberal abortion laws, using information on countries' abortion laws compiled by the Guttmacher Institute. ${ }^{2}$ We identified high-income countries using the World Bank country classifications by income level, for the year 2017. ${ }^{3}$ In conjunction with data collection on abortion incidence, we collected data from 2012 to 2018. We collected data for the most recent year available after 2010, and, when possible, we also collected data for the 10 years prior. Countries were categorised as having liberal abortion laws if abortion was legal without restriction or was legal on socioeconomic grounds, either with or without gestational limits. We also include New Zealand and Israel, where abortion is allowed to preserve a woman's mental health, because this ground is interpreted relatively liberally in these two countries. ${ }^{2}$ Among the 24 high-income countries for which data were available, abortion was available on request in 18 countries, on socioeconomic grounds in four, and for the mental health of the woman in two (table 1). ${ }^{4}$

To collect official abortion statistics, we searched the websites of statistical offices or relevant agencies for the most recent official abortion data available (online supplementary supporting table 1). When the search resulted in reports with data from previous years the data for up to 10 years prior were collated. When data were not available online, we contacted agencies directly and asked officials to complete a standardised questionnaire that gathered information from official records on the incidence of legally induced abortions and characteristics of abortions including gestational age and method. This questionnaire was distributed for a study on abortion incidence that began in 2014 and the questionnaires requested data on abortions up to 2017. For the United States, we utilised results from the Guttmacher Institute Abortion Patient Survey, ${ }^{5}$ as abortion statistics from the Centers for Disease Control and Prevention do not contain data for all states. ${ }^{6}$

As the legal status and legal indications of abortion can influence the method and gestational age of abortion, we collected information on the legal status, gestational age limits and exceptions, mandatory waiting periods, and conscientious objection clauses in a country (table 1 and online supplementary supporting table 2). For legal status and gestational age limit, we collected information from the Center for Reproductive Rights, ${ }^{7}$ and for exceptions to the gestational age limit, waiting periods and conscientious objection clauses, from the Global Abortion Policies Database. ${ }^{8}$ We also collected information from the Global Abortion Policies Database on whether misoprostol and/or mifepristone are recognised in a country, which was supplemented with information from Gynuity on the year mifepristone was registered. ${ }^{9}$

We categorised method of abortion into three types: surgical, medication (or medical) and other. It was not possible to further refine these categories due to differences in abortion reporting, method availability, and terminology between countries. For this review article, medication abortion refers to primarily the regimen of mifepristone and misoprostol, although if a country reported abortions obtained through misoprostol alone, they were also included in the total of medication abortions. In addition, the Netherlands and Canada report a category of surgical abortion plus medication abortion, and these abortions were classified as surgical abortions. The definition of other abortion varies by country and not all countries explicitly state what falls under this category, but it can include methods such as hysterotomy.

We collated gestational age data as follows: fewer than 9 weeks (up to 8 weeks and 6 days), 9-12 weeks, and 13 or more weeks. These categories reflect the most common classification of gestational age in country reports. Countries that use different classification categories are indicated in the footnotes of figure 3.

Of the 40 high-income countries with liberal laws in the world as of 2017 (as defined by the World Bank, and for countries with populations greater than one million), data were available on the method of abortion in 16 countries and on the gestational ages at which abortions were performed in 21 countries. In 10 countries, the data on abortions are from 2017; in the remaining countries, the most recent year for which data were available ranged from 2011 to 2016. The year of data available for each country can be found in online supplementary supporting table 3. Trend data were not available for all countries, and we present trends on the method of abortion for 11 countries, and the gestational age for 13 countries. The difference between data availability for gestational age and method is attributed to variations in what characteristics countries collect and report in their official abortions statistics. In Great Britain, Scotland reports its abortion statistics separately from England and Wales, and the categories used for gestational age and method differ slightly. Therefore the data for these geographic areas are presented separately in this analysis, but are counted as one country in the above tabulations. In addition, we refer to Great Britain rather than the United Kingdom due to the different abortion law in Northern Ireland.

We calculated percentage distributions in order to facilitate comparison between countries. In addition, due to concerns with abortion underreporting, percentage distributions have the advantage of being more reliable if abortion reporting is incomplete, as long as the level of underreporting doesn't vary by gestational age or method of abortion. We assessed the completeness of data for each country from the data collection methodologies in the country reports or published literature. Statistics that were assessed as 

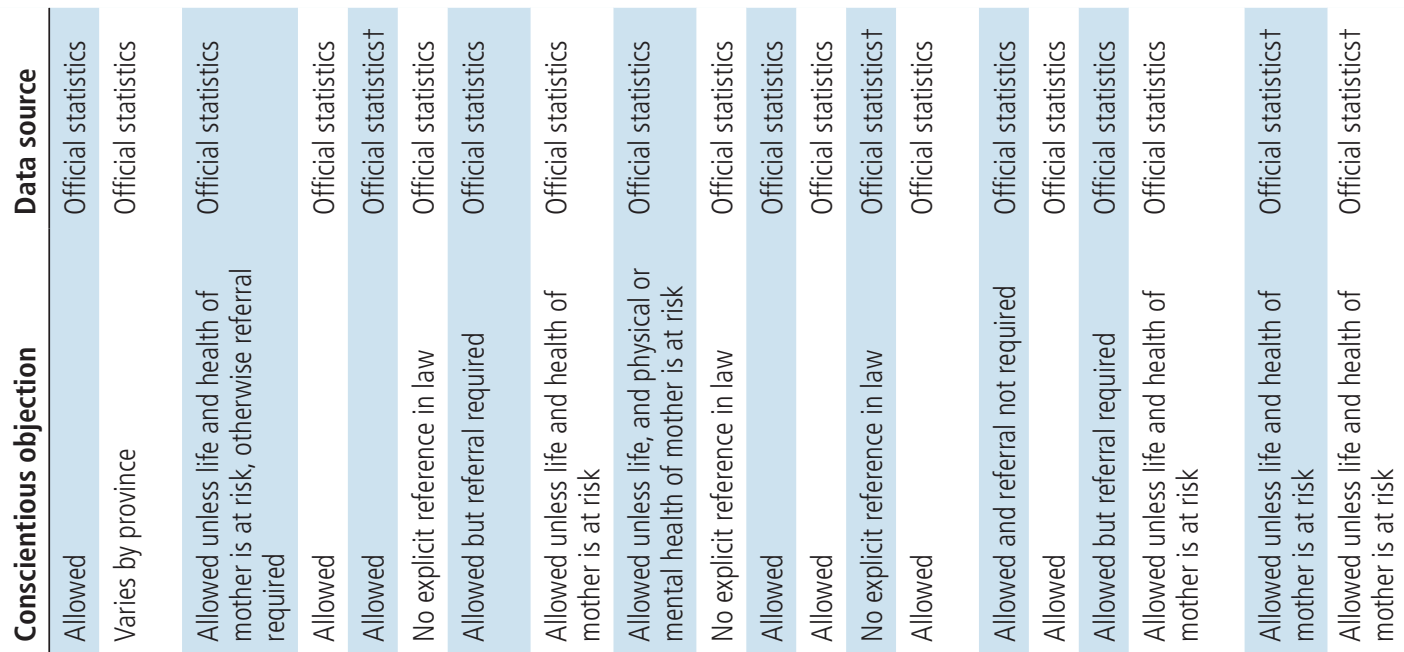

容.

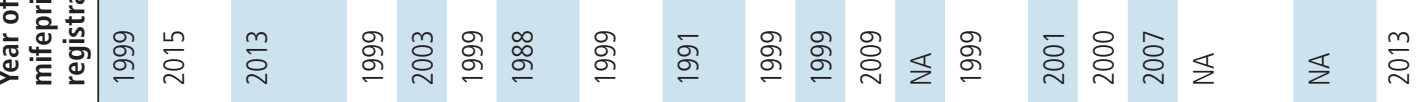

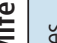

这

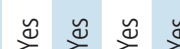

ֻั

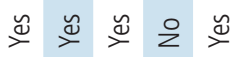

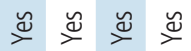

$2 \cong$

$\overline{\dot{े}}$

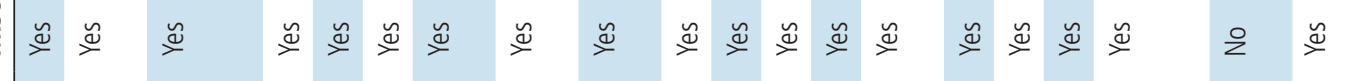

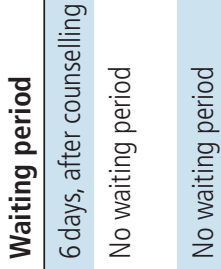

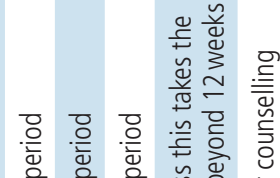

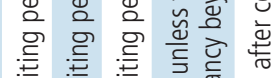

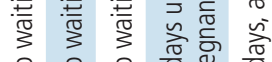

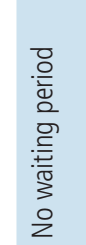

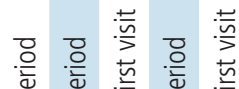

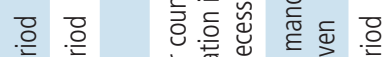

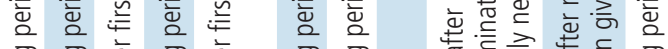

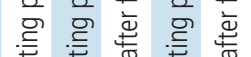

을 을

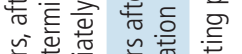

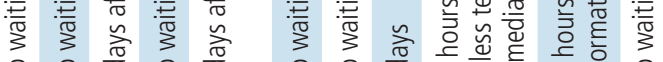

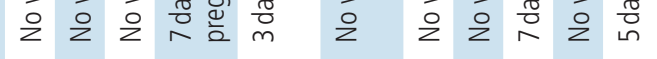

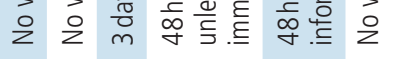

学

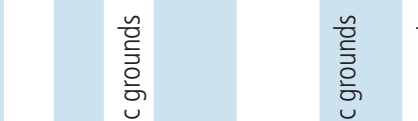

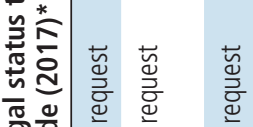

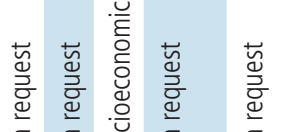

言

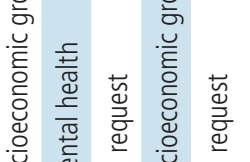

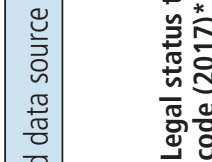

ธे ठ

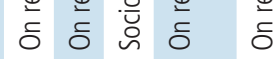

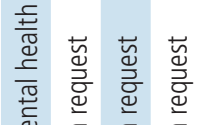

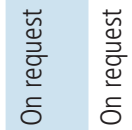

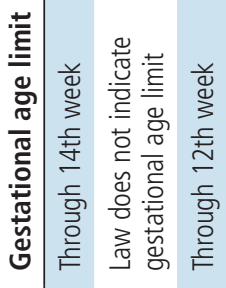

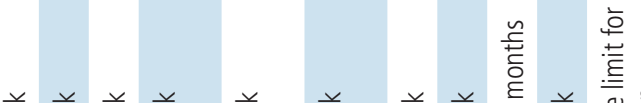

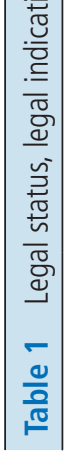

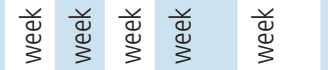

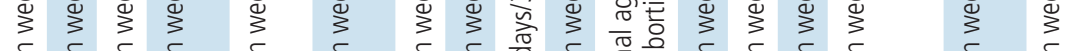

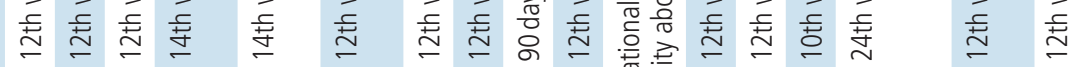

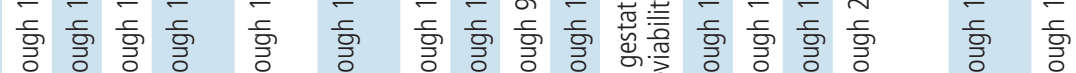

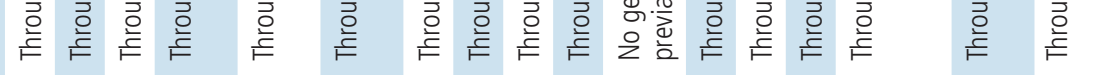


capturing at least $90 \%$ of all legal abortions within the country were classified as complete and footnotes indicate whether a country's data are incomplete.

When calculating the percentage distribution of abortions, abortions for which the gestational age or method of abortion were not specified were not included in the numerator or denominator unless non-specified abortions accounted for more than $10 \%$ of all abortions reported. That is, when non-specified abortions accounted for fewer than $10 \%$ of all abortions, we assumed the non-specified abortions had the same distribution according to gestational age and method. The only exception is for Canada, where $18.3 \%$ of all abortions were unspecified. In addition, in Canada, country statistics only report gestational age and method data for abortions performed in hospitals, which, according to country statistics, account for only about a third of all abortions in Canada. Despite this limitation, the data from Canada are included as they provide at least some insight into abortion provision in that country.

No ethical approval was required for this study as the data do not constitute human subjects research.

\section{RESULTS}

\section{Method of abortion}

In the majority of countries, medication abortion accounts for at least half of all abortions, with the highest proportions found in the Nordic countries of Finland (97\%), Sweden (93\%) and Norway (88\%) (figure 1). In almost all Northern Europe countries, medication abortion accounts for at least two-thirds of all abortions. In Western Europe, France and Switzerland have the highest proportion of medication abortions at $68 \%$ and $75 \%$, respectively.

In five countries, of which three are in Western Europe, surgical abortion accounts for over three-quarters of the abortion services. Southern Europe has the greatest subregional variation in abortion method, with surgical abortion accounting for $81 \%$ of abortions in Italy, compared with medication abortions accounting for $71 \%$ of all abortions in Portugal.

Over the past 10 years, all countries have seen an increase in the proportion of abortions that were medication abortions (figure 2). In Denmark, Estonia, England and Wales, France and Iceland, medication abortion is now the more common method of abortion. The change in Iceland is especially noteworthy as medication abortion only became available in Iceland in 2006. The proportion of abortions that were medication abortions has also increased in Belgium, Italy and Germany, although medication abortion still accounts for a small proportion of all abortions in these countries.

\section{Gestational age}

In 2017 , or the most recent year of available data, for almost all countries, over two-thirds of abortions 


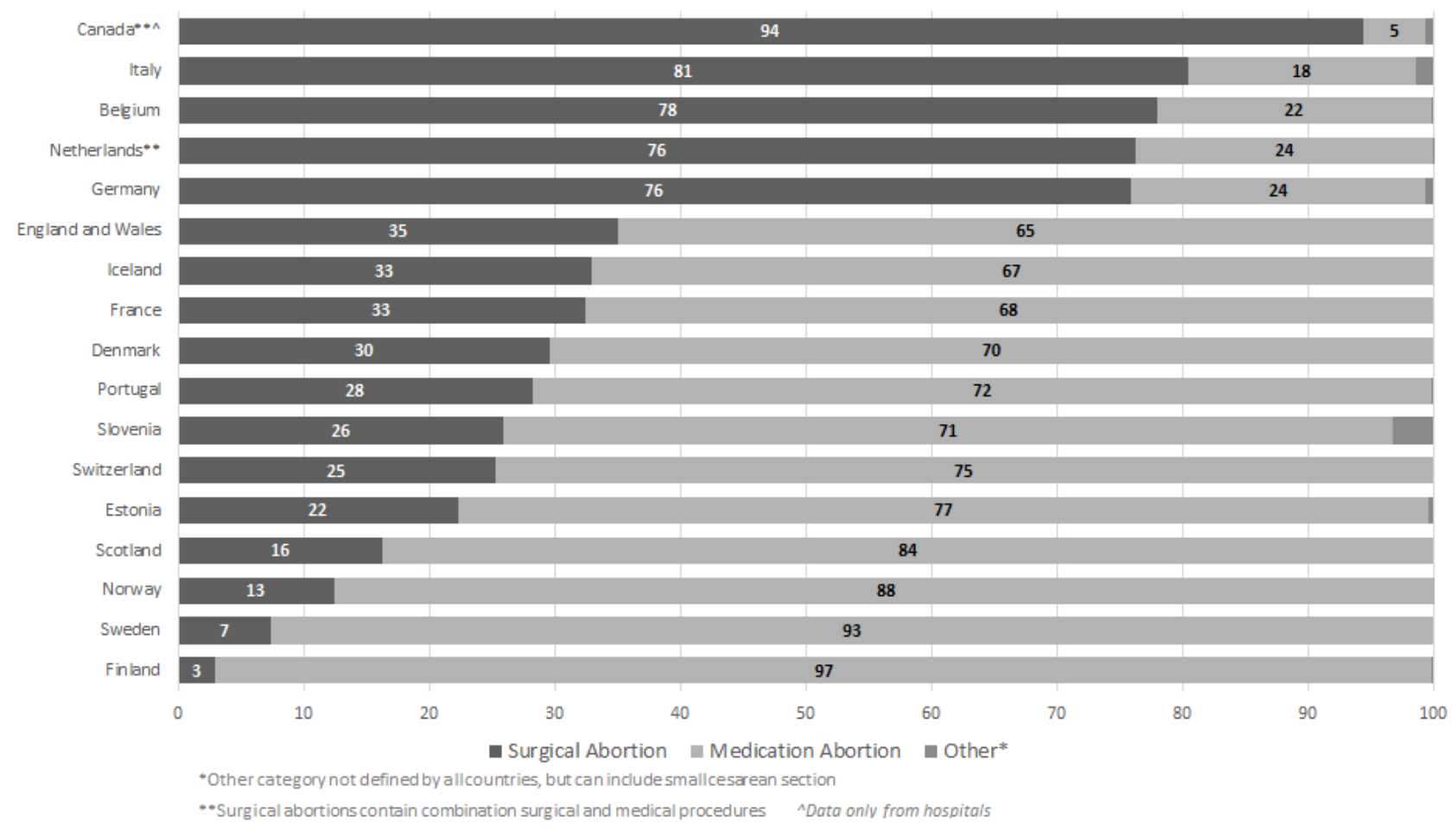

Figure 1 Percentage distribution of abortions by method of abortion, 2017.

occurred at less than 9 weeks gestation (figure 3). The percentage of abortions occurring at less than 9 weeks gestation ranged from $39 \%$ in Canada to $84 \%$ in Sweden. [NB. Abortion data in Canada are for hospitals only, which, according to country statistics, account for only about a third of all abortions in Canada.] New Zealand, Canada and Italy are the only countries where fewer than half of all abortions occurred at less than 9 weeks gestation; however, in all countries most abortions occurred by 10 or 11 weeks gestation. In

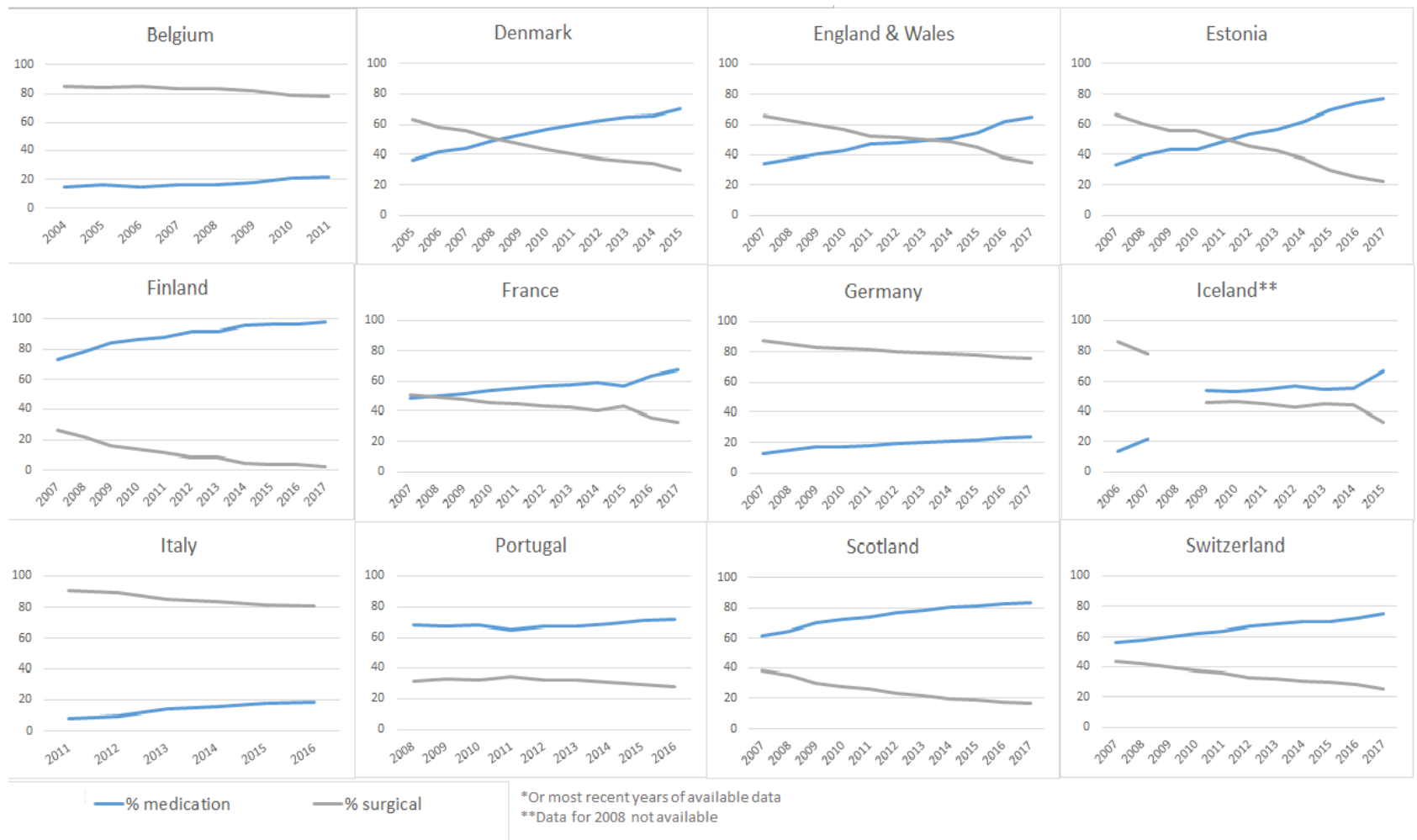

Figure 2 Proportion of medication and surgical abortions from 2007 to $2017^{*}$ 


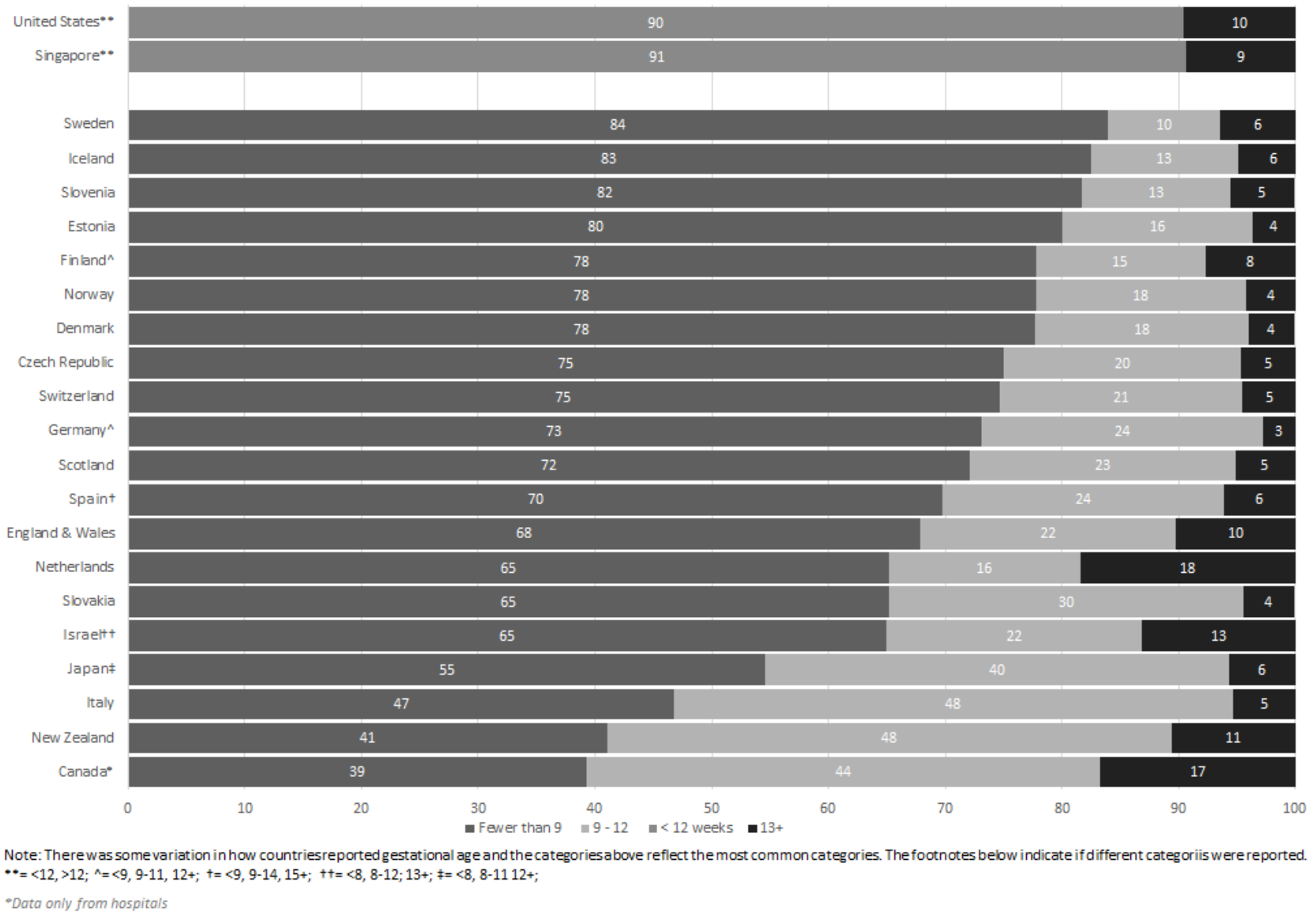

Figure 3 Percent distribution of abortions by gestational age, 2017.

the majority of countries over $90 \%$ of abortions occur before 13 weeks. In 10 countries, 95\% of abortions occurred before 13 weeks, with the highest proportion of abortions completed before 13 weeks in Germany (97\%). The proportion of abortions at 13 weeks and above was highest in the Netherlands, where $18 \%$ of abortions occurred after 13 weeks.

Over the past 10 years there has generally been an increase in the proportion of abortions that were obtained earlier than 9 weeks gestation (online supplementary supporting figure 1). There is a considerable range among countries: from an increase of two percentage points in Finland, to 25 percentage points in Germany. Although New Zealand currently has the lowest proportion of abortions that occur at less than 9 weeks gestation, this value has increased by 20 percentage points in the last 10 years. The Netherlands experienced small declines in the proportion of abortions that were obtained earlier than 9 weeks gestation.

In Norway, Sweden, and England and Wales, information about method of abortion by gestational age was available (online supplementary supporting table 4). In all three of these countries, medication abortions account for at least $83 \%$ of abortions performed at less than 9 weeks gestation. This is also seen in Scotland, where medication abortions account for $90 \%$ of all abortions at less than 9 weeks gestation (data not shown). In Sweden, mifepristone is given at the hospital/clinic and then women have the option to either take the misoprostol in the hospital/clinic or at home. ${ }^{10}$ In Sweden, 64\% of all abortions were medication abortions where misoprostol was taken at home, which accounted for $75 \%$ of all abortions performed at less than 9 weeks' gestation (data not shown). Between 9 and 12 weeks gestation, only England and Wales reported a higher proportion of surgical abortions versus medication abortions. Medication abortion continued to be the more utilised method in both Norway (68\%) and Sweden (78\%) for abortions performed between 9 and 12 weeksgestation.

Data were available on the percentage distribution of the abortions by gestational age of the pregnancy and age group of the women for Norway, Finland, Sweden, and England and Wales (online supplementary supporting figure 2) for 2017. In all of these countries, over $72 \%$ of all abortions occurred at less than 9 weeks gestation for all six age groups. However, women aged under 20 years consistently have a lower proportion of abortions at less than 9 weeks, and a higher proportion at 9-12 weeks compared with older age groups. Generally all age groups experienced abortions at 13 weeks and above at very similar proportions, except in Finland where women aged over 40 
years had a slightly higher proportion of abortions at 13-18 weeks.

\section{DISCUSSION}

The provision of abortion services has changed in the past decade. Medication abortion accounts for at least half of all abortions in the majority of countries. Also in the majority of countries, over $90 \%$ of all abortions were completed before 13 weeks, and more than two-thirds of abortions occurred before the first 9 weeks of gestation. Over the past 10 years there has been an increase in both the proportion of abortions that were medication abortions, and the proportion that were obtained before 9 weeks gestation.

Over the past 10 years, the dramatic increase in the proportion of abortions that are medication abortions is likely reflective of factors related to both supply of and demand for the procedure. There is substantial variation across countries with respect to the year in which misoprostol and mifepristone was first approved for pregnancy termination, but the length of time that the method has been available is not necessarily correlated with the prevalence of the method. France was the first country, other than China, to license the use of misoprostol and mifepristone for early medical abortion in $1988,{ }^{11}$ and since then countries have approved this combination regimen at different points, with Canada being the most recent among this group of countries to legalise the combination of misoprostol and mifepristone in 2015. Japan and Slovakia are the only countries cited in this review where combination mifepristone and misoprostol have not been approved for abortion services, although misoprostol alone is recognised as a method. ${ }^{8}$

The proportion of abortions that were medication abortions may also depend in part on the level of government and public sector support for this method, and on the adequate training of providers. Although France was one of the first countries to approve the use of misoprostol and mifepristone, in the 1990s medication abortion was very highly regulated, and only in 2001 was a law introduced to allow the provision of medication abortion outside of hospitals, ${ }^{11}$ and medication abortion has been available outside of hospitals since 2005. ${ }^{12}$ Portugal, in contrast, has a higher proportion of medication abortions; almost three-quarters of abortions occur in public hospitals, and $98 \%$ of abortions performed in hospitals are medication abortions. This may partially be due to the fact that abortion is only legal in Portugal up to 10 weeks gestation. Overall in Western Europe there continues to be a high proportion of surgical abortions. However in Belgium, the latest available data are from 2011 so it not possible to discern if this proportion has changed recently.

Mandatory waiting periods can also influence the proportion of abortions that are medication abortions. Ten of the 24 countries in this review require waiting periods after a woman's first appointment (table 1). These waiting periods range from 48 hours in Scotland and Singapore, to seven days in France and Italy. ${ }^{8}$ Longer waiting periods can reduce women's choice of abortion method because it increases the gestational age at which the abortion is performed. For example, in France, medication abortion can only be performed up to 49 days gestation, yet the mandatory 7-day waiting period may impact whether a women is eligible for a medication abortion at the time of her procedure. ${ }^{11}$

The proportion of abortions that occur earlier than 9 weeks gestation increased in the majority of countries in this review. The increase in abortions earlier than 9 weeks is likely closely related to the increased availability of medication abortion, since when medication abortion was first approved, the recommended protocol is for a medication abortion to occur under 63 days or 9 weeks gestation. ${ }^{13}$ This trend might also be due to the rise in technologies for earlier detection of pregnancy, and the widespread availability of pregnancy tests that provide accurate results at early gestations. ${ }^{13}$ There is a strong connection between these two factors, which when coupled with increased access to abortion services, may result in an increase in the proportion of abortions occurring earlier than 9 weeks gestation.

The proportion of abortions conducted after 9 weeks remained high in a few countries. In Canada, the available data suggest that a large proportion of abortions are obtained after 13 weeks, but data are only available for abortions performed in hospitals, where abortions after 13 weeks are likely overrepresented. In addition, $18.6 \%$ of the reported abortions in Canada are unspecified, which could bias these findings if the unspecified abortions are not evenly distributed across gestational age.

A country's gestational age limits for legal abortion can affect the distribution of gestational age of abortion within a country, and in neighbouring countries, if women have to travel to seek an abortion after 13 weeks. For example, there is no gestational age limit for legal abortion in the Netherlands, and the large proportion of abortions done after 13 weeks in the Netherlands are partly due to abortions obtained by non-residents. In 2015, non-residents accounted for $12.6 \%$ of women obtaining abortions in the Netherlands, and the majority of those women sought abortions at 13 weeks and above, compared to only 5.1\% of Dutch women who had abortions at 13 weeks and above. ${ }^{14}$ Other evidence found that in $200672 \%$ of abortions at 13 weeks and above in the Netherlands were to women of non-Dutch residence and origin. ${ }^{15}$ Therefore, regardless of how rare abortion at 13 weeks and above is in a given country, the Dutch experience suggests that the demand for abortions at greater than 13 weeks exists to some extent in all countries. Safe and legal abortions at 13 weeks and 
above should be available to all women who need them.

Conscientious objection clauses exist for most countries considered in this review (table 1). With adequate and timely referrals and a sufficient number of providers, conscientious objection can potentially exist without being a barrier to care. ${ }^{16}$ However, examples in Europe indicate that it can delay or prevent women from accessing abortion care ${ }^{17}$ and potentially cause women to seek abortions after 13 weeks gestation. Data on the impact of conscientious objection are limited, but, in Italy, a country with a lower proportion of abortions at less than 9 weeks gestation, the prevalence of conscientious objection has led to a shortage of abortion providers in Italy. It is estimated that $82 \%-91 \%$ of providers in Rome and the surrounding areas are conscientious objectors, and abortion services are only provided in $60 \%$ of Italian hospitals. ${ }^{18}$ The prevalence of conscientious objection likely delays women's access to services, and as indicated in a statement by the Council of Europe in 2016, causes Italian women to travel abroad, or "resort to ending their pregnancy without the support of competent health authorities". ${ }^{19}$

This article, the first review of gestational age and method of abortion across high-income countries, has several limitations. While the completeness of data were assessed for each country from official reports, the findings may be influenced if abortion statistics are underreported or incomplete. If countries have incomplete data, these findings rely on the assumption that the level of underreporting of abortion does not vary by gestational age or method of abortion, however this information is not available. Anecdotal evidence suggests that medication abortion is more prone to underreporting than surgical abortion, especially with the increase of access to medication abortion outside of the healthcare system. Regulations and common practices within the healthcare system that we were not able to quantify or cite may also drive some of the findings. Similarly, as most data are not available by country of residence, the legal status and/or gestational age limits of abortion within a country and neighbouring countries may also influence the distribution of gestational age. Finally, the findings from these countries may not be generalisable to countries without official statistics, low-income countries, or countries with restrictive abortion laws, and indicate a need for additional research. In particular, findings from low-income countries with liberal abortion laws could shed light on service provision and barriers to care in those settings.

Options for terminating pregnancies are important as studies have found that when given the choice, many women have strong preferences for one method of abortion over the other. ${ }^{20-23}$ Reasons for selecting medication abortion include fear of clinical procedures or anaesthesia, and the perception that it is "more natural" and similar to a miscarriage. ${ }^{20}$ Conversely, women select surgical procedures because they are "faster and easier". ${ }^{21}$ However the percentage distribution of abortion methods in a country does not necessarily indicate a woman's ability to choose a method. Health system factors such as method availability, provider preference, waiting periods and/or gestational age limits can all influence the method a woman chooses.

Examining the distribution of abortions by method of abortion and gestational age at time of termination is one step in understanding the factors that drive these distributions, and this review highlights the need to understand if the observed distributions are a function of women's preferences or of barriers to care. More research is needed on the proportion of women obtaining an abortion who used the method of their choice, to shed light on whether women have the resources and options they need to terminate their pregnancies the way they want to. Ultimately, this evidence should enable policy makers and service providers to consider measures needed to ensure women can access safe services that align with their preferences in a timely manner.

Acknowledgements The authors gratefully acknowledge data assistance provided by Lorraine Kwok and Cynthia Beavin. The authors also thank Susheela Singh, Akinrinola Bankole and Evert Ketting for their comments on earlier drafts.

Contributors Both authors contributed to the conceptualisation of the paper. Drawing on methodologies from earlier papers by GS and colleagues, AP conducted data collection and analysis. Both authors developed the outline of the paper, and AP wrote the first draft. Both authors reviewed and substantively edited subsequent drafts.

Funding This work was made possible by UK Aid from the UK Government and the Dutch Ministry of Foreign Affairs. The views expressed are those of the authors and do not necessarily reflect the positions and policies of the donors.

Competing interests None declared.

Patient consent for publication Not required.

Provenance and peer review Not commissioned; externally peer reviewed.

Open access This is an open access article distributed in accordance with the Creative Commons Attribution Non Commercial (CC BY-NC 4.0) license, which permits others to distribute, remix, adapt, build upon this work noncommercially, and license their derivative works on different terms, provided the original work is properly cited, appropriate credit is given, any changes made indicated, and the use is noncommercial. See: http://creativecommons.org/licenses/by-nc/4. $0 /$.

\section{REFERENCES}

1 Sedgh G, Bearak J, Singh S, et al. Abortion incidence between 1990 and 2014: global, regional, and subregional levels and trends. Lancet 2016;388:258-67.

2 Singh S, Remez L, Sedgh G, et al. Abortion Worldwide 2017: Uneven Progress and Unequal Access. Guttmacher Inst 2018 https://www.guttmacher.org/report/abortion-worldwide-2017 (accessed 24 Oct 2018). 
3 World Bank. World Bank Country and Lending Groups

- World Bank Data Help Desk. https://datahelpdesk. worldbank.org/knowledgebase/articles/906519 (accessed 22 Dec 2017).

4 Center for Reproductive Rights. The World's Abortion Laws. 2014 https://www.reproductiverights.org/sites/crr.civicactions. net/files/documents/AbortionMap2014.PDF (accessed 14 Apr 2017).

5 Jones RK, Jerman J. Time to Appointment and Delays in Accessing Care Among U.S. Abortion Patients. New York: Guttmacher Institute, 2016.

6 Jatlaoui TC. Abortion Surveillance - United States, 2014. MMWR Surveill Summ 2017:66.

7 Center for Reproductive Rights. The World's Abortion Laws, 2017, 2018. https://www.reproductiverights.org/sites/crr. civicactions.net/files/documents/AbortionMap2014.PDF. (accessed 14 Apr 2017).

8 World Health Organization, Human Reproduction Program. The Global Abortion Policies Database. gapp. http://srhr.org/ abortion-policies/ (accessed 22 Dec 2017).

9 Gynuity Health Projects. Mifepristone approvals, 2017. http://gynuity.org/downloads/resources/biblio_ref_lst_mife. pdf.

10 Socialstyrelsen. Statistik om aborter 2017. Sweden: 2018.

11 Winikoff B, Hassoun D, Bracken H. Introduction and provision of medical abortion: a tale of two countries in which technology is necessary but not sufficient. Contraception 2011;83:322-9.

12 Vilian A, Rey S. 216700 interruptions volontaires de grossesse en 2017. 2018. France: DREES.
13 World Health Organization, editor. Safe abortion: technical and policy guidance for health systems. 2nd ed. Geneva: World Health Organization, 2012.

14 Twisk D, Wijsen C. Landelijke abortusregistratie 2015. Netherlands: Rutgers, 2016.

15 Loeber O, Wijsen C. Factors influencing the percentage of second trimester abortions in the Netherlands. Reprod Health Matters 2008;16:30-6.

16 Johnson BR, Kismödi E, Dragoman MV, et al. Conscientious objection to provision of legal abortion care. Int J Gynaecol Obstet 2013;123 Suppl 3:S60-S62.

17 Heino A, Gissler M, Apter D, et al. Conscientious objection and induced abortion in Europe. Eur J Contracept Reprod Health Care 2013;18:231-3.

18 Chavkin W, Swerdlow L, Fifield J. Regulation of conscientious objection to abortion. Health Hum Rights 2017;19:55-68.

19 Day M. Italy's women are finding it harder to get abortions as number of pro-choice doctors fall. BMJ Br Med J Online Lond 2016:353 http://dx.doi.org.ezproxy.cul.columbia.edu/.

20 Kanstrup C, Mäkelä M, Hauskov Graungaard A. Women’s reasons for choosing abortion method: a systematic literature review. Scand J Public Health 2017;1403494817717555.

21 Moreau C, Trussell J, Desfreres J, et al. Medical vs. surgical abortion: the importance of women's choice. Contraception 2011;84:224-9.

22 Henshaw RC, Naji SA, Russell IT, et al. Comparison of medical abortion with surgical vacuum aspiration: women's preferences and acceptability of treatment. BMJ 1993;307:714-7.

23 Ho PC, Pc H. Women's perceptions on medical abortion. Contraception 2006;74:11-15. 


\section{Correction: Trends in the method and gestational age of abortion in high-income countries}

Popinchalk A, Sedgh G. Trends in the method and gestational age of abortion in high-income countries. BMJ Sexual \& Reproductive Health 2019;45:95-103. doi: 10.1136/bmjsrh-2018-200149

In this article, the following changes should have been made in the published version. On page 1 the second key message should have read 'at least 90\% of abortions occur before 13 weeks.

In the discussion section, the sentence 'These waiting periods range from 48 hours in Scotland and Singapore' should have said 'These waiting periods range from 48 hours in Slovakia and Singapore.

In table 1, the gestational age limit has been updated in the countries Great Britain, Iceland, Israel, Japan and New Zealand. The updated data reads as follows;

\begin{tabular}{ll}
\hline Great Britain & Through 24th week \\
Iceland & Through 16th week \\
Israel & No gestational age limit specified \\
Japan & Through 21st week \\
New Zealand & Through 20th week
\end{tabular}

In supplementary table 2, the data should have been updated as follows:

online supplementary file 2

\section{() \\ OPEN ACCESS}

Open access This is an open access article distributed in accordance with the Creative Commons Attribution Non Commercial (CC BY-NC 4.0) license, which permits others to distribute, remix, adapt, build upon this work non-commercially, and license their derivative works on different terms, provided the original work is properly cited, appropriate credit is given, any changes made indicated, and the use is non-commercial. See: http://creativecommons.org/licenses/by-nc/4.0/.

(C) Author(s) (or their employer(s)) 2019. Re-use permitted under CC BY-NC. No commercial re-use. See rights and permissions. Published by BMJ.

BMJ Sex Reprod Health 2019;45:e1. doi:10.1136/bmjsrh-2018-200149corr1

Check for updates 